\title{
Ionosphere Parameters Changing by Interactive Tropical Cyclones according to Cosmos-1809 and Intercosmos Bulgaria-1300 Satellite Data
}

\author{
B. Boychev ${ }^{1}$, G. Belyaev ${ }^{2}$, V. Kostin ${ }^{2}$, O. Ovcharenko ${ }^{2}$, E. Trushkina ${ }^{2}$ \\ ${ }^{1}$ Space Research and Technology Institute - Bulgarian Academy of Sciences \\ ${ }^{2}$ Institute of Terrestrial Magnetism lonosphere and Radio Wave Propagation RAS
}

E mail (belyaev@izmiran.ru)

Accepted: 20 December 2017

\begin{abstract}
The data analysis of the on-board instruments set of the Cosmos-1809 and IKB-1300 satellites is presented for the following events. Continuous sequence of tropical cyclones (TCs) after the Mounts Pinatubo and Hudson eruptions in 1991. Sequences of 3 super-typhoons in the Western Pacific in November 1990. Sequences of 5 hurricanes in the Atlantic Ocean in September 1981. It is shown that the effects of the several interacting TCs impact on the ionosphere differ from those of single TCs. The distribution of electron fluctuations and density, VLF-ELF oscillations, and other plasma parameters of the upper ionosphere varies at different stages of development of tropical disturbances. Models of TCs interaction that change the parameters of the ionosphere are proposed. An important role is played by acoustic oscillations generated in TCs. The strongest volcanic eruptions in the twentieth century threw a significant amount of aerosols into the stratosphere. It is discussed how stratosphere changes for interacting TCs and perturbations after volcanic eruptions apparently cause a redistribution of infrasound along the TCs track which can lead to the formation of new TCs.
\end{abstract}

(c) 2018 BBSCS RN SWS. All rights reserved

Keywords: tropical disturbance, interacting cyclones, satellite, external ionosphere

\section{Introduction}

Tropical cyclones (TCs) are the most powerful processes in the atmosphere, redistributing the energy stored in the oceans (Holton et al., 2003). The Annual Tropical Cyclone Reports of the Joint Typhoon Warning Center (JTWC) collect all tropical weather activity in the Northern and Southern Hemispheres, from 180 degrees longitude westward to the east coast of Africa. The National Hurricane Center (NHC) is the division of the United States' National Weather Service responsible for tracking and predicting weather systems within the tropics between the Prime Meridian and the 140th meridian west poleward to the 30th parallel north in the northeast Pacific Ocean and the 31st parallel north in the northern Atlantic Ocean. Information on meteorological parameters at altitudes to the lower stratosphere, calculations of the trajectories of the motion of the TCs is presented in these sites.

However, there are many unclear questions about the physics of TCs development. Earlier, the authors of the reports (Belyaev et al., 2015), (Kostin et al., 2015), (Isaev et al., 2010) attempted to explain the features of the upper ionosphere plasma, which were observed from satellites over the TCs. It was suggested that a flooded stream of neutral atoms is formed above the stratosphere anticyclone over the TCs. This mechanism redistributes the ionosphere chemical constituents which can be distinguished up to different ionosphere heights and from large horizontal distances of the TC meridian (Guha et al., 2016). Individual noninteracting neutral particles can reach up to different ionosphere heights: oxygen $\approx 52 \mathrm{~km}$, hydrogen $\approx 208 \mathrm{~km}$, and helium $\approx 831 \mathrm{~km}$ due to different directional speed $V_{T}=(2 \mathrm{kT} / \mathrm{m})^{1 / 2}$ (Belyaev et al., 2015). The heating of the stratosphere and the formation of a jet can occur because of the self-organization of nonlinear acoustic waves propagating upward (Aburjania et al., 2013), (Rudenko and Sapozhnikov, 2004). Oscillations of a vertically stratified dissipative atmosphere is reviewed in (Dmitrienko and Rudenko, 2016). Intensive lightning discharges in the TCs can be a source of acoustic waves (Sindelarova et al., 2009). Analysis of gravitywaves produced by intense tropical cyclones is reviewed in (Chane Ming et al., 2010). Intensive infrasonic waves generated in the TC are called "Voice of Sea" (Semenov, 2013).

The energy cycle of wind waves on the sea surface is reviewed in (Golitsyn, 2010). Quasi-linear model of interaction of surface waves with strong and hurricane winds is reviewed in (Troitskaya and Rybushkina, 2010). Neutral atoms of the jet flying above $\sim 230 \mathrm{~km}$ move along ballistic trajectories and reach heights of more than $1000 \mathrm{~km}$ where they can be ionized. Selected electromagnetic effects with their participation were observed by electro-magnetic satellite complexes (Belyaev et al., 2015), (Kostin et al., 2015). The flooded jet is supported by surface oscillations that propagate upward along the jet. Feedback is created by the generation of infrasonic vibrations that propagate down the stream. Infrasound reaches the ocean surface, extends along the surface and enhances ocean-atmosphere heat exchange. This leads to an intensification of TCs.

However, in many cases there are interacting TCs (Dong and Neumann, 1983), (Yaroshevich and Ingel', 2006), (Pokhil and Glebova, 2011). Back in the 1970s the important role of the stratosphere state for the selforganization of atmospheric processes was statistically demonstrated (Sadler, 1979). In the present work, the satellites Cosmos-1809 and IKB-1300 data during the development of interacting TCs are presented. Particular attention is paid to the development of the 
TCs and its impact on the ionosphere after the eruption of the Mounts Pinatubo and Hudson in 1991.

These eruptions were the strongest in the 20th century. The eruption in August to October 1991 was a large plinian eruption with a VEI of 5 that ejected 4.3 $\mathrm{km}^{3}$ bulk volumes $(2.7$ cubic $\mathrm{km}$ of dense rock equivalent material). Parts of the glacier melted and ran down the mountain as mud flows (see glacier run). In addition to the ash, a large amount of sulfur dioxide gas and aerosols were ejected in the eruption. These contributed to those already in the atmosphere from the even larger Mount Pinatubo eruption earlier in the year and helped cause a worldwide cooling effect over the following years. Ozone was also depleted, with the Antarctic ozone hole growing to its largest levels ever recorded in 1992 and 1993. Effects both from volcanic explosions (Cheng et al., 1992) and changes in the propagation of radio waves in the lowfrequency range have been observed in the ionosphere (Labytzke, 1994). Total electron content anomalies associated with global VEI4+ Volcanic eruptions during 2002-2015 is reviewed in (Li et al.,2016).

\section{Influence of the Mounts Pinatubo and Hudson eruptions on the dynamics of the TCs and ionosphere according to the Cosmos-1809 satellite data}

Analysis of the results of the electron density $\mathrm{Ne}$ measurements in the upper ionosphere by the Cosmos-1809 satellite during the global monitoring of plasma parameters in 1990-1993 showed that after the strongest eruptions of Pinatubo and Hudson volcanoes in the summer of 1991 the average value of $\mathrm{Ne}$ decreased. The change in the plasma density (measure units - telemetric volts) along the trajectory of the satellite is shown in Fig. 1, where Ne before Pinatubo eruption is shown on panel 1, Ne after eruption - on panels 2-7. Atmosphere temperature determines $\mathrm{Ne}$ in ionosphere therefore average value decrease of $\mathrm{Ne}$ after three weeks of Pinatubo eruption is related with beginning of atmosphere cooling. Indeed, strong volcanic eruptions lead to a climate cooling for 1-4 years (Eliseev and Mokhov 2008), (Climate Change 2007).

However, in some cases, when the satellite passed over the zone of TCs impact, anomalous parameters of the ionosphere were noted. Figure 1 shows the individual fragments of $\mathrm{Ne}$ monitoring during periods of interacting TCs development. The numbers of revolutions that are longitudinally shifted by 26.1 degrees, shifted in time by 104 minutes, shifted according to local time by 4 minutes are indicated. The moments of passing the latitude of the nearest TCs are marked. The TCs parameters are taken from the JTWC annual report (Rudolph and Guard, 1991).

Walt was the first super typhoon in the western North Pacific this year. On May 12, it was in the stage of alone typhoon of the 5th category (with maximum sustained 1- minute mean speed of surface wind of $140 \mathrm{kt}$ or $72 \mathrm{~m} / \mathrm{s}$ ). The revolution 22197 passed at LT = 1 over Walt (panel 1 fig.1). But the anomalous $\mathrm{Ne}$ increase is noted at the revolution 22200, when the morning terminator passed through Walt and ionization of the neutral atoms injected by the typhoon into the ionosphere occurred. Quantitative estimates of ionosphere effects during the passage of the terminator over individual TCs require detailed consideration. This is beyond the limited scope of this work. A similar situation was considered in detail above TCs Harry in (Belyaev et al., 2015).

Walt developed as part of an equatorial convective process known as a "westerly burst" (Brand, 1970), (Lander, 1990) at the same time a twin, Tropical Cyclone Lisa, developed in the Southern Hemisphere by 5-7 May. Figure 2 shows the change in $\mathrm{Ne}, \mathrm{El} 40 \mathrm{~Hz}$ and $4600 \mathrm{~Hz}$ ( $\triangle \mathrm{f}=\mathrm{F} / 8$ - channel width) in the morning sector at the orbits closest to the two TCs interaction zone the intensity of which was below $30 \mathrm{kt}$. There is a slight increase in $\mathrm{Ne}$ at the revolutions west of 22106, passing along the meridian of the TCs, which corresponds to an additional vertical removal of hydrogen atoms from the lower ionosphere above the center of Walt.

The confirmation of this fact is an increase in the frequency of the lower hybrid oscillations and the output of the spectral maximum of the noise from the $\mathrm{E} 4600 \mathrm{~Hz}$ channel, which is presented on the revolution 22109. The second minimum in the $\mathrm{E} 4600 \mathrm{~Hz}$ channel at latitude of 25 degrees is associated with the entry of neutral excited hydrogen atoms moving along inclined trajectories to the area of influence of the Chinese 3SA transmitter. An electron flux with energies of $3-5 \mathrm{eV}$ is generated over the VLF transmitters in the ionosphere, which ionizes the excited hydrogen atoms. This effect was noted in (Kostin et al., 2015). The same features in the $\mathrm{E} 4600 \mathrm{~Hz}$ channel are noted at the 22106-22108 revolutions. The ionization of the flux of excited helium atoms above the center of the Lisa TCs enhances the cyclotron oscillations at the helium frequency, which is noted in the E1 $40 \mathrm{~Hz}$ channel.

The continuous sequence of TCs from July to December 1991 arose in the western part of the Pacific Ocean after the Mounts Pinatubo and Hudson eruptions. The trajectories of typhoons in July 1991 and their characteristics are given in Fig. 3. Different typhoons are highlighted in different colors. 


\section{Cosmos-1809}

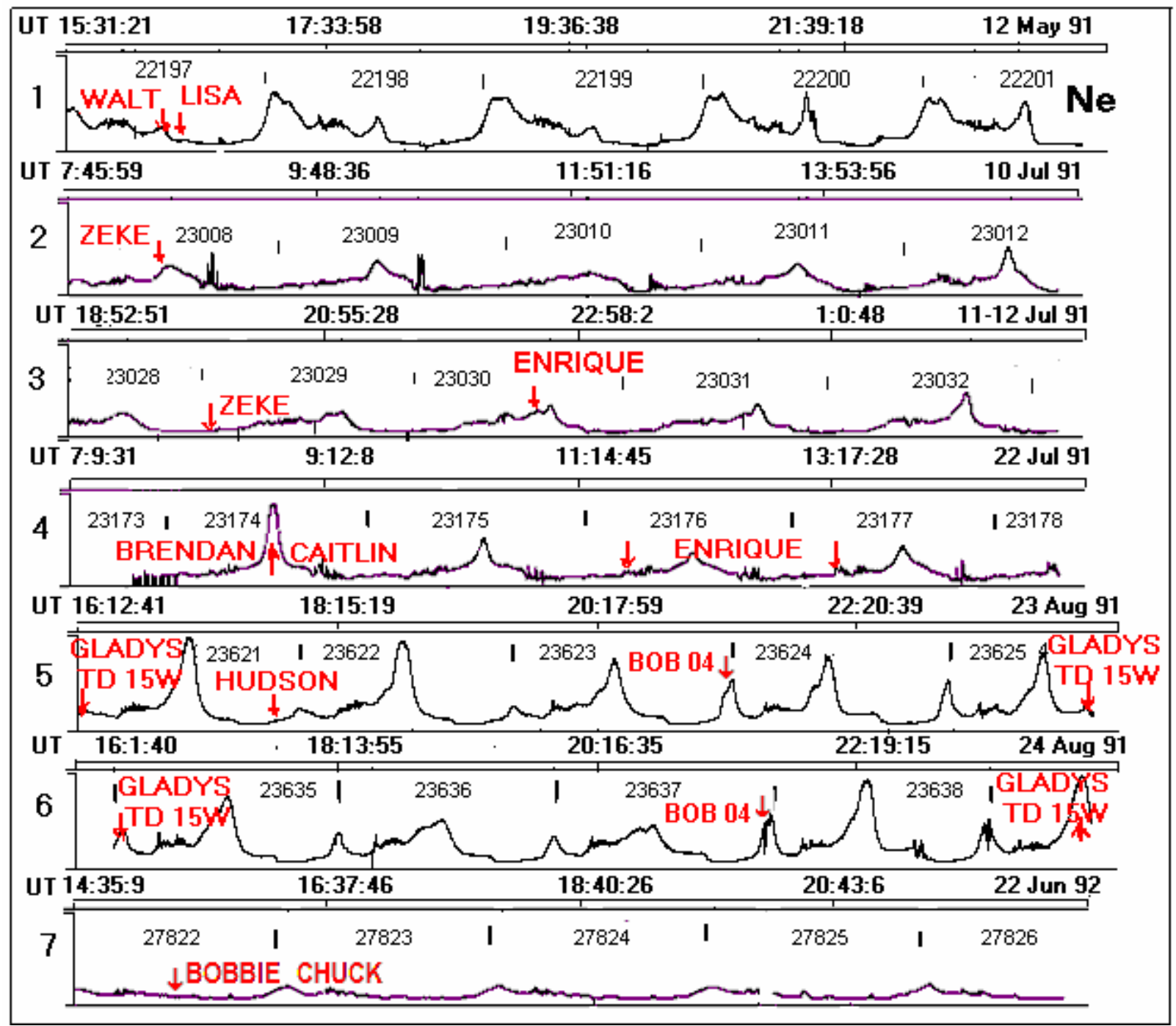

Fig.1. Y-axis - Ne (telemetric volts, $0-6 \mathrm{~V}$ for all panels) changing along the trajectory of the satellite Cosmos-1809 before and after the Mount Pinatubo eruption. The numbers of revolutions are indicated and the moments of the latitude of the nearest TCs passing are marked. Time and measurement dates are indicated at the top of each panel.

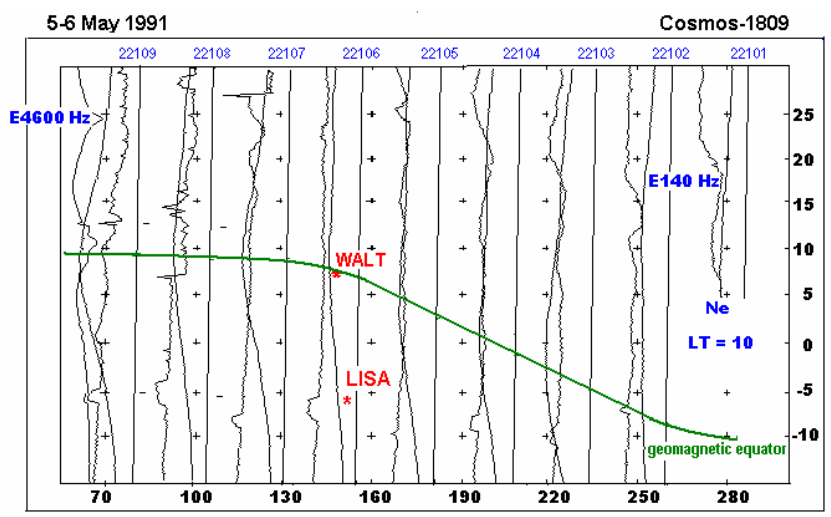

Fig.2. Parameters of the upper ionosphere plasma on the revolutions closest to the development zone of the pair TCWalt and Lisa at the phase of the tropical storm.

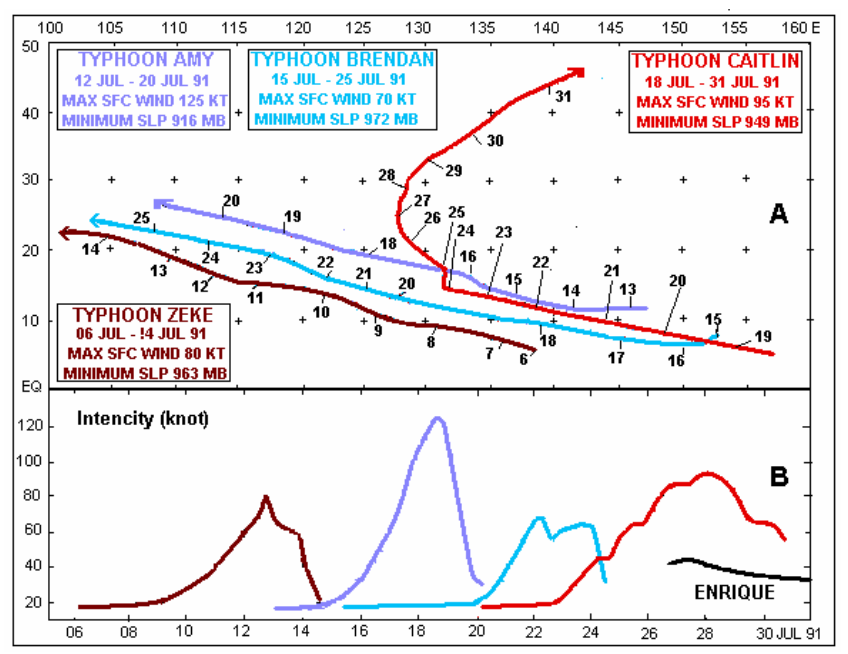

Fig.3. Tracks and intensity of the Pacific Ocean Typhoons in July 1991. 
In Fig. 3A the highest surface (SFC) wind speed averaged over a 1-minute period of time and see-level pressure (SLP) minimum is additionally given. On the scale (3B), the intensity of the tropical storm (TS) Enrique after crossing the dateline is added. TS Enrique formed in the eastern Pacific basin (panel 3 in Fig. 1), where it reached its peak intensity as a category 1 Hurricane. Enrique lasted for 6 days becoming a remnant low, shortly after entering in the central Pacific. As Enrique approached the International Dateline, the system started to redevelop.

From Figures 1 and 3 it can be seen that the disturbed stratosphere, after the eruption of Mount Pinatubo, contributes to the emergence of a consistent chain of interacting TCs. There are two types of interaction. The first type - when the developed TCs reaches its maximum, then at a distance of $\sim 3,500 \mathrm{~km}$ there is a tropical depression (TD), which is sharply increased at the phase of the decline of the developed TCs. The second type - when the distance between TCs becomes $\sim 2000 \mathrm{~km}$, then there is a synchronous increase in the intensity of both TCs. In more detail this case will be analyzed in the next section.

The first TC in this chain was TC Zeke. Parameters of the ionosphere plasma along the TC Zeke meridian during the birth of TC Amy (LT = 4) are shown in figure 4.

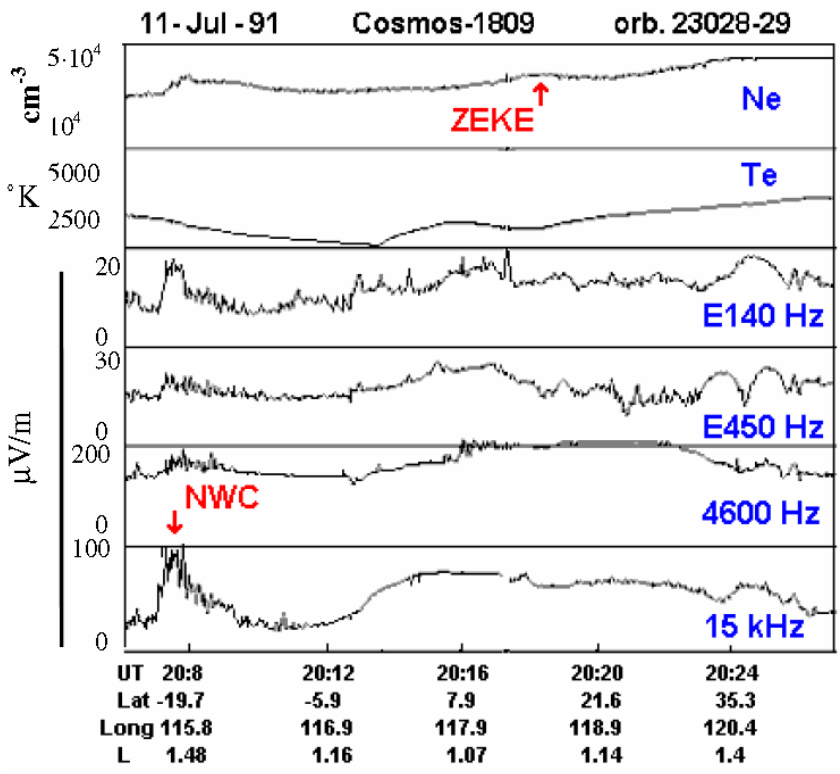

Fig.4. Upper ionosphere plasma parameters above the typhoon Zeke.

There is a slight $\mathrm{Ne}$ increase at the zenith and heating of electrons in the vicinity of the geomagnetic equator. Strong anomalies of electrostatic oscillations are observed over the Australian NWC VLF transmitter (21.8 S $114.2 \mathrm{E}$ ), which operated at a frequency of 19.8 $\mathrm{kHz}$. Ionosphere anomalies were observed from the satellites Cosmos-1809 and DE-I above the given transmitter and in the magneto-conjugated region when there were no developed TCs in the vicinity of about $3000 \mathrm{~km}$. (Sonwalkar et al., 1994). Investigations of the effect of high-frequency radiation from the Sura heating stand on the ionosphere with the help of the Cosmos-1809 satellite have shown that abnormal regions (up to $1000 \mathrm{~km}$ ) arise over remote VLF transmitters (Kostin et al., 1993). Such effects are explained by the fact that metastable helium, hydrogen, and oxygen atoms emerge from the energy absorption region, which are easily ionized by the epithermal electrons emerging above the VLF transmitters (Kostin et al., 2016). In the ionosphere near the cyclotron frequencies of helium, hydrogen, and the lower hybrid frequency over powerful energy sources, the original features of the spectrum of electrostatic oscillations are observed (Belyaev and Kostin, 2015). These spectral maxima are recorded in the frequency channels $140 \mathrm{~Hz}, 450 \mathrm{~Hz}$ and $4600 \mathrm{~Hz}$ with bandpass filters $F / \triangle \mathrm{f}=8 \mathrm{ELF}-\mathrm{VLF}$ of the Cosmos-1809 satellite wave complex.

The periodic structures in the El40 and E450 channels can be associated with acoustic oscillations arising in the Zeke typhoon, as far as the conclusions about Harry TCs in (Belyaev et al., 2015). Acoustic oscillations in the surface layer above the ocean can extend to several thousand $\mathrm{km}$ and amplify the TD. Infrasound from different sources can propagate for a long distances (Chunchuzov et al; 2011), (Liszka, 1974). Meteorological situation significantly influence on the infrasound propagation (Lobycheva et al., 2005). Interaction a hurricane wind and ocean surface was considerated in quasi-linear model for determining the aerodynamic drag coefficient in (Troitskaya and Rybushkina, 2008). Helical self-organization of moist convective atmospheric turbulence in a rotating, nonhomogeneous atmosphere forming TC was considered in (Levina and Montgomery, 2014).The anomalous $\mathrm{Ne}$ values on July 22 at the 23174 revolution (panel 4 in Fig. $1)$, were caused by the effect of the interacting Brendan and Caitlin at the ionosphere.

In August 1991 the acoustic impact of explosive eruptions of the Hudson volcano led to a significant $\mathrm{Ne}$ increase in the daytime ionosphere (panels 5 and 6 in Fig 1). It should be noted an interesting event when the typhoon Gladys (tropical depression Bob 04) and Chinese

VLF transmitter acted on the ionosphere at one L-shell (Fig.5). A stable cavity was formed at this L-shell in the E4600 $\mathrm{Hz}$ channel, which is connected with the increased injection of hydrogen atoms in this region.

By 15 June 1992, the monsoon trough became established in its normal climatological location across the South China Sea, the central Philippine Islands and extended into the Caroline Islands. By 21 June, Bobbie's formation (TD) in the central Caroline Islands coincided with that Chuck over the central Philippine Islands. The binary pair remained within $1390 \mathrm{~km}$ of each and appeared to undergo relative cyclonic rotation about a common midpoint for three days. The characteristic changes of $\mathrm{Ne}$ are presented in panel 7 of Fig. 1. The chain of typhoons in this region was formed until December.

In June and July the hurricanes of the Atlantic Ocean were not formed. The events of 1992 require further detailed consideration. 


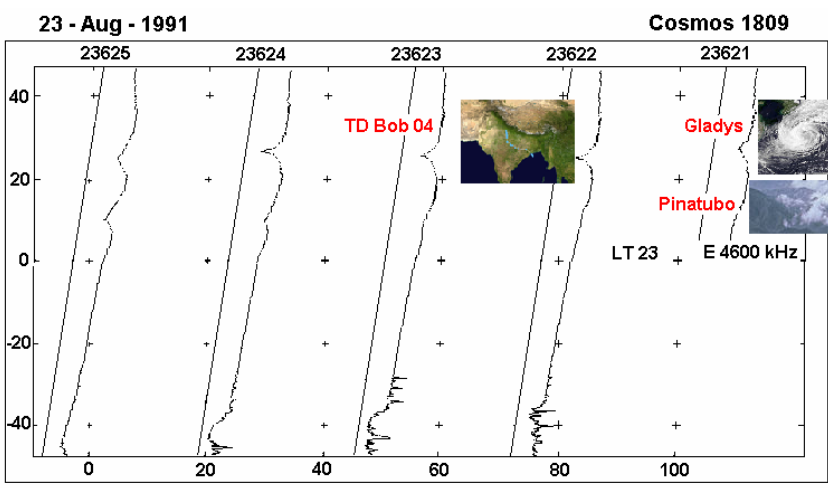

Fig. 5. The intensity of the upper ionosphere plasma oscillations in the channel $4600 \mathrm{~Hz}$ (near the lower hybrid resonance) on revolutions west of the typhoon Gladys and the Mount Pinatubo 2 weeks after the eruption of the Mount Hudson.

\section{lonosphere during the development of Page and Owen super typhoons in the Asia- Pacific trough.}

Very strong ionosphere effects were observed during the amplification of up to 5 categories of interacting TCs. The inclusion on November 21, 1990 of the Cosmos-1809 satellite equipment coincided with the beginning of the enhancement of the Page, Owen and Sina TCs.

The "stopping" of the tropical storm Page (the trajectory in two days passed a loop with a width of $\sim 2$ degrees) caused an intensification of the tropical depression Owen and Sina TCs. First warning due to improved upper and lower level organization, increased deep convection, increasing wind speeds in the synoptic data. Tropical Storm Owen starting its explosive intensification phase. The trajectories of the TCs and their characteristics are shown in Fig 6.

In Fig. 7 it is shown the change of $\mathrm{Ne}$ on November 21 , observed at 10 consecutive revolutions at the $L T=$ 19.5 sector. A sharp decrease in $\mathrm{Ne}$ at the latitude of the TCs Page and Owen, and a wide Ne maximum (lasting for $1000 \mathrm{~km}$ ) at the latitude of the Sina TC pay attention to the turns 19818 -19819. At this time TCs were located in the midnight sector. The distance between them was about $2000 \mathrm{~km}$. There was an intensification of Owen from $20 \mathrm{kt}$ to $80 \mathrm{kt}$ (Fig. 6). For single TC of this intensity, two Ne maxima were observed in the upper ionosphere: a narrow maximum $(300-400 \mathrm{~km})$ was at the zenith and a wide maximum (more than $1000 \mathrm{~km}$ ) was at $\mathrm{L}$ shells that based upon the E layer above the TCs (Isaev et al. , 2010), (Kostin et al., 2015).

It is assumed that in the case of interacting TCs, the stratosphere wind deflects the trajectories of acoustic oscillations excited in the Page TC, and they are transported along the Page TC track to the Owen TC, which is amplified, as shown in Fig. 8. Accordingly, at night, Ne decreases, as shown in Fig. 7. The abovedescribed differs from the mechanism of troposphere interaction of two rotating TCs ( Fujiwhara effect), which is observed when they are away from each other by less than $1400 \mathrm{~km}$ (Pokhil et al., 2013). All these assumptions require a detailed theoretical research.

Then TCs Page, Owen and Sina synchronously developed during the week to typhoons of the fifth category which was observed on November 28. In the evening sector, there was $\mathrm{Ne}$ decrease by three orders of magnitude on $L \sim 3$, and a wide maximum of the plasma pressure was formed along the geomagnetic equator. In the morning sector, the moving ionosphere disturbances zones are identified according to the device for measuring ELF-VLF plasma oscillations. Relaxation of ionosphere disturbances was observed on December 3.

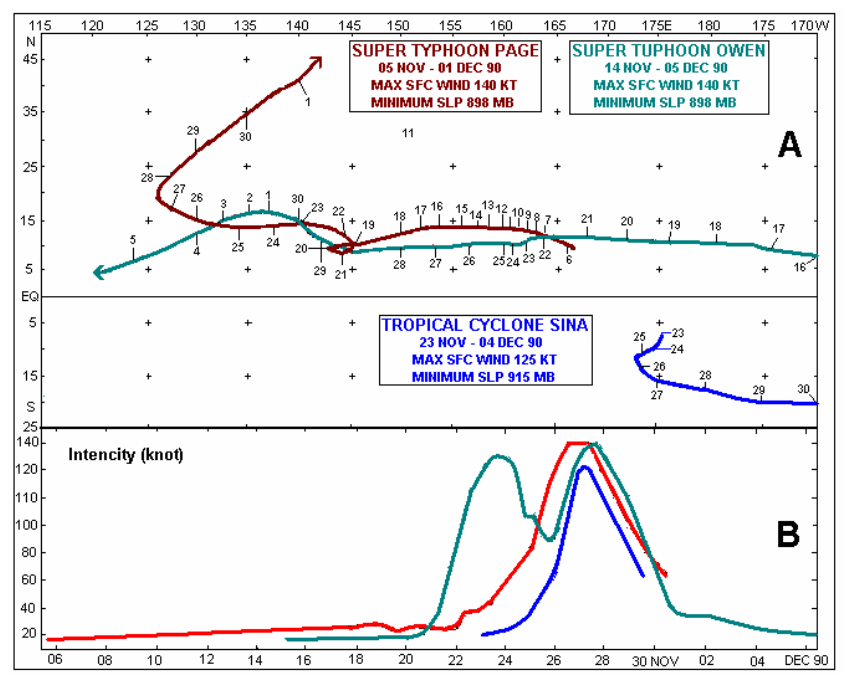

Fig.6. Tracks of the Super Typhoons Page, Owen and Sina.

21 - Nov - 90

Cosmos -1809

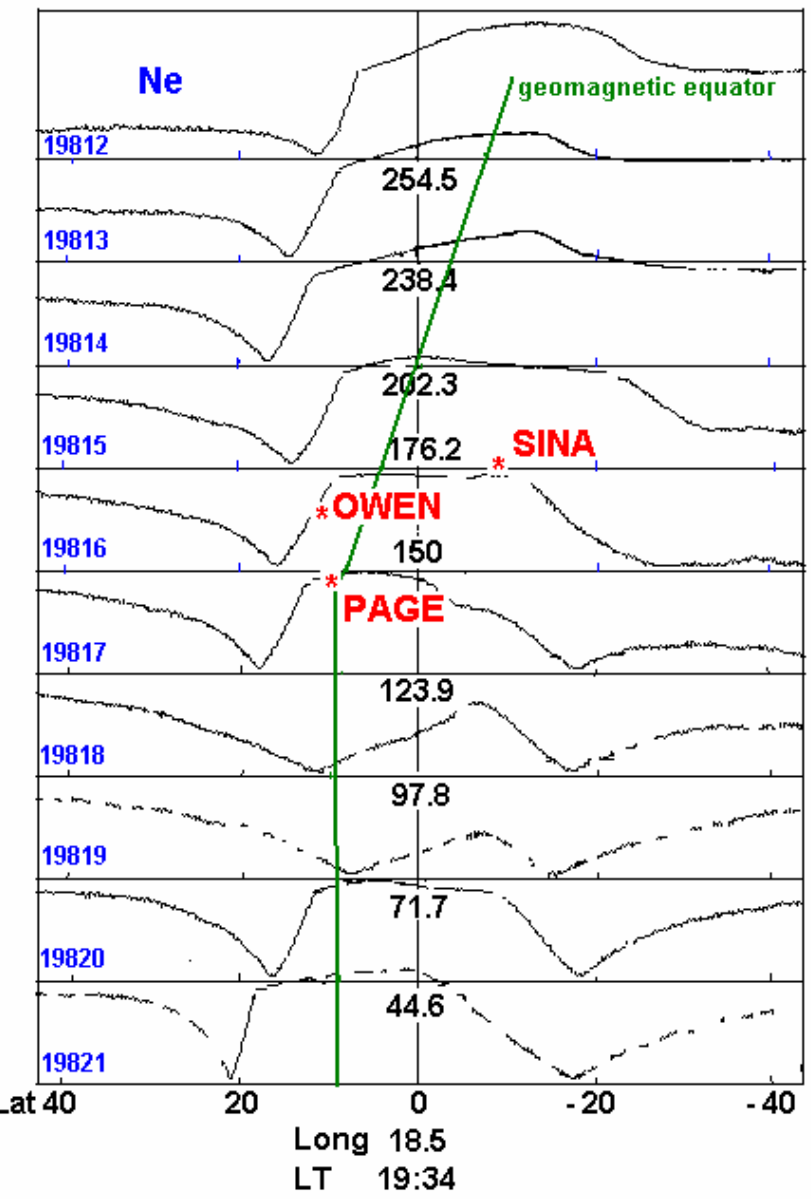

Fig.7. Ne change in the ionosphere evening sector on the day of TC Page, Owen and Sina intensive interaction. $\mathrm{Y}$-axis - Ne (telemetric volts, $0-6 \mathrm{~V}$ for all panels). 


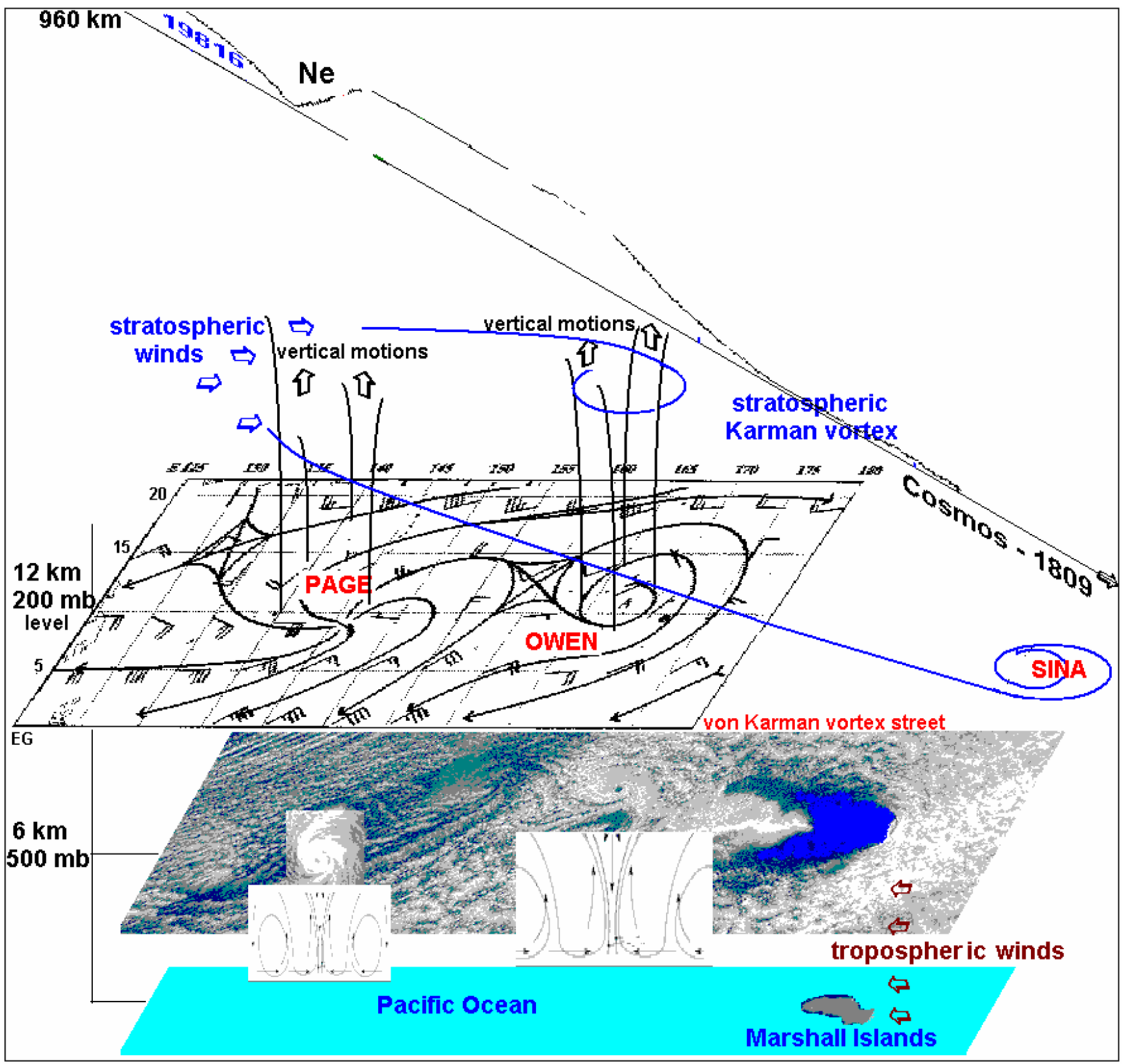

Fig.8. Scheme of TC Page, Owen and Sina interaction.

The interaction scheme for Page, Owen and Sina is presented in Fig.8. This Landsat 7 image of clouds off the Chilean coast near the Juan Fernandez Islands shows a unique pattern called a von Karman vortex street. It is assumed that the same mechanism underlies the emergence of tropical disturbances (TD) Page, Owen and Sina. TD will be strengthened if the mechanism increasing the heat exchange ocean-atmosphere works. It is shown in Fig. 8 that TS Page with developed vertical movement above the tropopause is blown by a stratosphere wind which follows from the synoptic chart. In this case the Karman vortices must also be formed. When the vortices in the stratosphere coincide vertically with vortices in the troposphere, a redistribution of the oscillation energy of the wind takes

place. The amplified infrasonic oscillations in the TD following the first TC reach the ocean surface and enhance heat exchange. There is an intensification of TD. In this case the TD Owen was strengthened to a typhoon of category 5 first. Then there was TD Sina increase to fifth category TC. When they retired from the TC Page, it also increased to a typhoon of category 5. Thus the interacting TCs differ from a single TC over which the vertical movement in the stratosphere is transformed into a flooded jet. Note that the standard consideration of the interaction of tropical cyclones with each other and with different atmospheric structures (Pokhil et al., 2013) does not take into account stratosphere and ionosphere effects. 


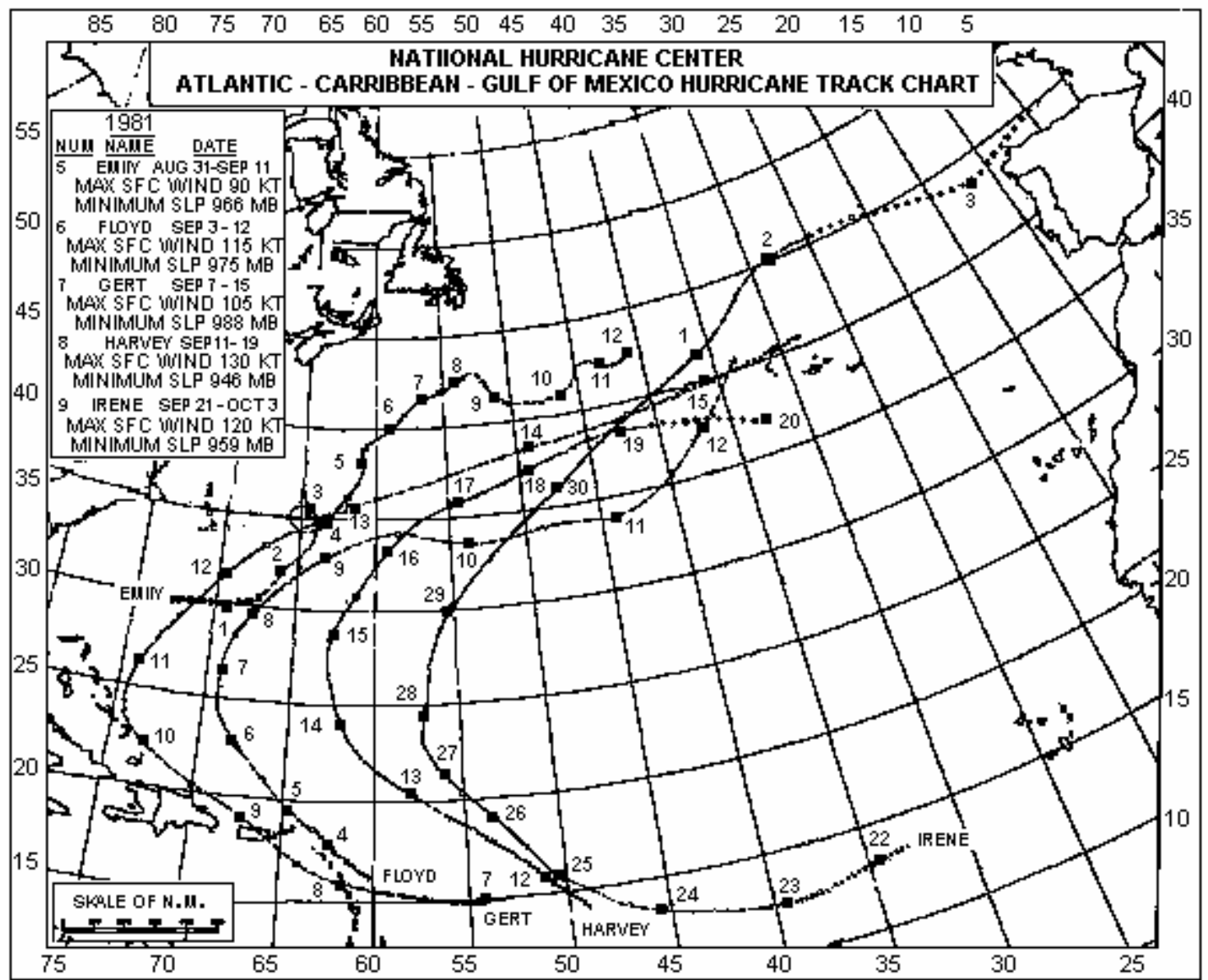

Fig.9. Tracks of the Tropical Storms and Hurricanes in September 1981.

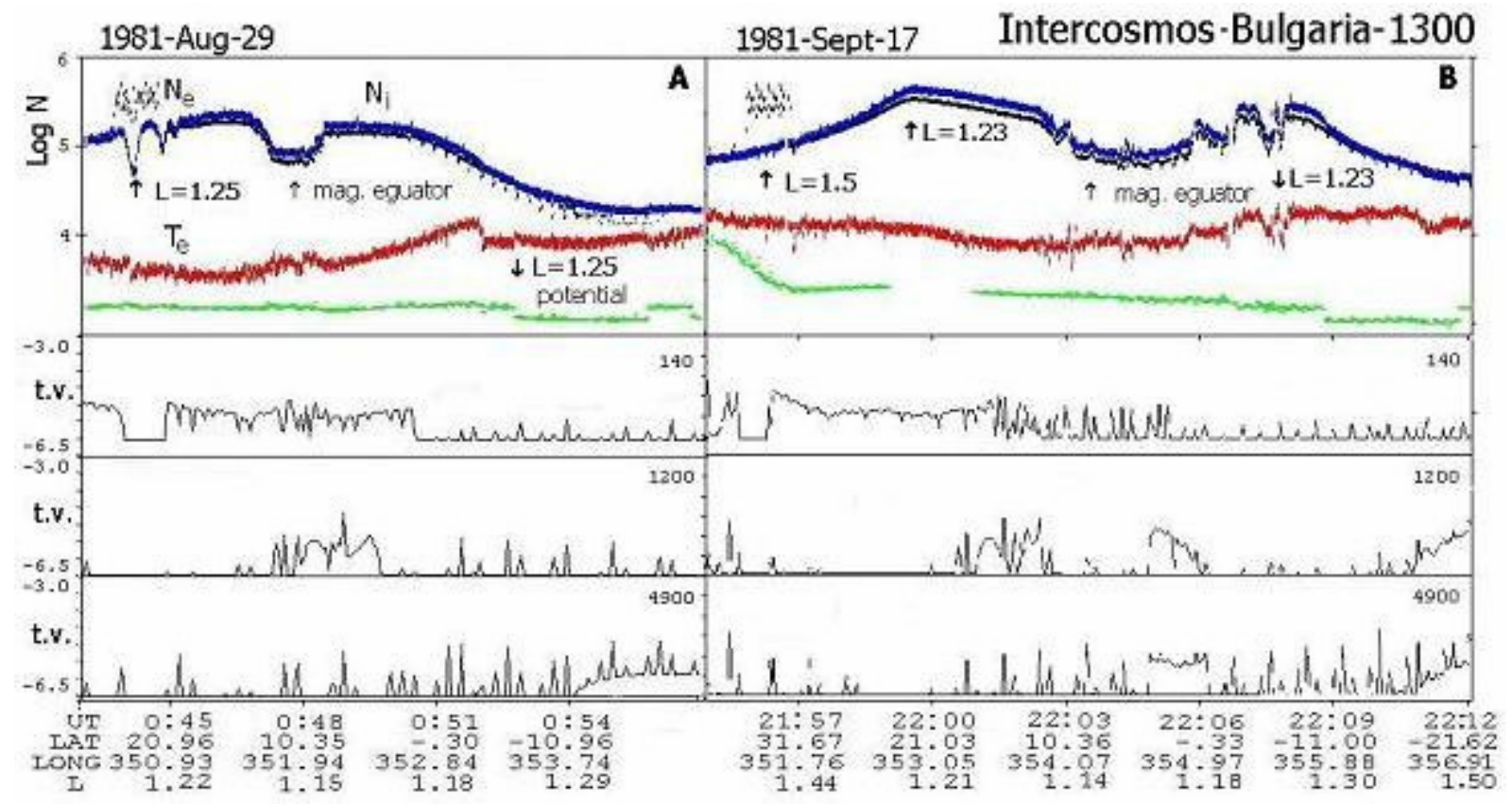

Fig. 10. Upper ionosphere plasma parameters during the hurricane chain generation in the Atlantic Ocean (A) and in the period of its completion by the interaction of hurricanes Harvey and Irene. 


\section{lonosphere during the development of a chain of hurricanes from African tropical waves according to the satellite IKB-1300 data.}

The study of the ionosphere features over the Brazilian anomaly was one of the first tasks of the IKB1300 satellite. Most of the working inclusions occurred over the Atlantic Ocean. In the 1981 season, only in September there was a continuous sequence of hurricanes in the Atlantic Ocean (Lawrence and Pelissier, 1982). It is shown in Fig. 9 the trajectories of these hurricanes and their characteristics.

A dissipating frontal zone in the Atlantic off the southeast United States coast gradually developed into a low pressure system during the last few days of August. TS Emily was a large system with a broad area of light winds and little convection around the center. Blocked temporarily by a large high pressure system passing north of the storm, TS Emily moved through a complete loop on the $3^{\text {rd }}$ and $4^{\text {th }}$ of September. The interaction of these two systems produced large swells over the western Atlantic.

Floyd was the first of the series of four September hurricanes which followed similar tracks, curving northward out of the tropics through the western Atlantic. Gert was first detected on satellite pictures as an area of cloudless moving off the African coast on 1 September. Harvey was the strongest hurricane to date of the 1981 season. Throughout its deepening period 13 - 15 September the center of the hurricane was located along the western periphery of a welldeveloped upper level anticyclone as depicted on $200 \mathrm{mb}$ charts. During the weakening stage after 15 September, the upper level anticyclone remained centered between latitudes $25 \mathrm{~N}$ and $30 \mathrm{~N}$. The system which was to become Hurricane Irene moved off the west coast of Africa on 19 September as a high amplitude perturbation on the intertropical convergence zone cloudless.

It is shown in Fig. 10A one of the precursors of the amplification of TD Emily - a characteristic cavern in $\mathrm{Ne}$ which was previously shown by the authors in (Kostin et al, 2015). If a second TC develops at a distance of $\sim 20$ degrees, the $\mathrm{Ne}$ structure and other plasma parameters of the upper ionosphere change. So the weakening of hurricane Harvey (1981) led to the intensification of hurricane Irene, with the center of the stratosphere anticyclone locating between them. A number of local depressions of $\mathrm{Ne}$ with scales along the trajectory of the satellite to several hundred kilometers were observed in the ionosphere.

\section{Summary}

Analysis of plasma parameters of the upper ionosphere over interacting TCs shows:

1. At the stage of incidence of the intensity maximum of the first TC, a second TC increases in its trace at a distance of $\sim 2500 \mathrm{~km}$. This situation arose after the eruption of the Mounts Pinatubo and Hudson. One possible explanation is: at the stage of dissipation of the tropical cyclone, the wave striations are excited in the stratosphere, which are carried by the stratosphere wind. These fluctuations intensify the tropical disturbance that follows. In the ionosphere, a reduced content of the electron density is marked.

2. For interacting superstructures TCs with synchronously varying intensities local anomalous fall of $\mathrm{Ne}$ in the ionosphere are detected. This situation is explained by interaction of a perturbed region over TCs with a stratosphere wind and exchange of energy of acoustic oscillations.

3. A binary interacting TCs when they are closed then $760 \mathrm{~nm}(1400 \mathrm{~km})$ distance of each other start rotating about a common midpoint (Fujiwhara effect) apparently injecting hydrogen into the ionosphere. Excitation of electrostatic oscillations near the cyclotron frequency of hydrogen and a significant increase in the frequency of the lower hybrid oscillations are observed.

4. A continuous TCs sequence, as in the case of hurricanes in September 1981, may be related to the effect of blocked temporarily by a large high pressure system. A tropical disturbance is formed on an easterly wave moving off African coast. In the ionosphere, anomalous $\mathrm{Ne}$ dips and excitation of VLF oscillations were observed.

The obtained results can serve as an indicator of the appearance of interacting TCs for which the calculation of the trajectories and the intensity of the TCs in meteorology is a problem. Further investigation of these problems is required. 


\section{References}

Aburjania, G.D., Kharshiladze, O.A. and Chargazia, K.Z.: 2013, Geomagn. Aeron. 53, 750.

Belyaev, G., Boychev, B., Kostin, V., Trushkina, E. and Ovcharenko, O.: 2015, SunGeo. 10, 31.

Belyaev, G.G., and Kostin, V.M.: 2015, in V.D. Kuznetsov (ed.). Electromagnetic and Plasma Processes from the Solar to the Earth's Interior, IZMIRAN, p.170. www.izmiran.ru/IZMIRAN75/IRP/Belyaev.pdf.

Brand, S.: 1970, J. Appl. Meteorology. 9, 433. Chane Ming, F., Chen, Z. and Roux, F.: 2010, Annales Geophysicae. 28, 531.

Cheng, K., Huang, Y.N. and Chen, S.W.: 1992, J. Geophys. Res. 97, 11695.

Climate Change 2007: The Physical Science Basis/Eds: Solomon S., Qin D., Manning M. et al. Cambridge/New York: Cambridge University Press, 2007, 996.

Chunchuzov, I. P., Kulichkov, S. N., Popov, O. E., Waxler, R., and Assink, J.: 2011, Izvestiya. Atmospheric and Oceanic Physics. 47,540 .

Dmitrienko, I.S. and Rudenko, G.V.: 2016, J. Atm. Solar-Terr. Phys. 142, 120.

Dong, K. and Neumann, C.J.: 1983, Monthly Weather Review. 111, 945.

Eliseev, A.V., and Mokhov, I.I.: 2008, Izvestiya. Atmospheric and Oceanic Physics. 44, 671.

Golitsyn, G.S.: 2010, Izvestia Atmospheric and Oceanic Physics. $46,6$.

Holton, J.R., Curry, J.A. and Pyle, J.A.: 2003, Encyclopedia of Atmospheric Sciences, Academic Press, London, p. 2780.

Isaev, N.V., Kostin, V.M., Belyaev, G.G., Ovcharenko, O.Ya. and Trushkina, E.P.: 2010, Geomagn. Aeron. 50, 243.

Kostin, V.M., Romanovski, Yu.A., Chmyrev, V.M., Sinelnikov, V.M., Afonin, V.V., Borisov, N.D., Zuzin, V.A., Isaev, N.V., Komrakov, G. P., Mikhailov, Yu.M., Ovcharenko, O.Ya., Petrov M.S., Selegej, V.V., Sobolev, Ya.P. and Trushkina, E.P.: 1993, Cosmic Research. 31, 67.

Kostin, V.M., Belyaev, G.G., Boychev, B., Trushkina, E.P. and Ovcharenko, O.Ya.: 2015, Geomagn. Aeron. 55, 246.

Kostin, V.M., Belyaev, G.G., Mikhailov, Yu.M., Trushkina, E.P., Ovcharenko, O.Ya. and Sobolev, Ya.P.: 2016, Twelfth annual conference "Plasma physics in Solar system", IKI RAN. 215.

Labytzke, K.: 1994, J. Atm. Terr. Phys. 56, 1227.

Lander, M.A.: 1990, Monthly Weather Review. 118, 1194.

Lawrence, M.B. and Pelissier, J.M.: 1982, Monthly Weather Review. 110, 852.

Levina, G.V., and Montgomery, M.T.: 2014, Doklady Earth Sciences. 458, 1143.

Li, W., Yue, J., Guo, J., Shen, Y. and Yang, Y.: 2016, J. Volcanology and Geothermal Research. 325, 98.

Liszka, L.: 1974, J. Acoust. Soc. Am. 56, 1383.

Lobycheva, I.Yu., Ponomarev, E.A., Rudenko, G.V., and Sorokin, A.G.: 2005, Atmospheric and Oceanic Optics. 18, 174.

Pokhil, A.E. and Glebova, E.S.: 2011, Russian Meteoroloqy and Hydroloqy. 36, 569.

Pokhil, A.E., Glebova, E.S. and Smirnov, A.V.: 2013, Russian Meteoroloqy and Hydroloqy. 38, 141.

Rudenko, O.V. and Sapozhnikov, O.A.: 2004, Physics-Uspekhi. 47, 970.

Rudolph, D.K. and Guard, C.P.: 1991, Annual Tropical Cyclone Report.

Sadler, J.C.: 1979, Naval Environmental Prediction Research facility Technical Paper. No. 2-76.

Semenov, A.G.: 2013, J. Geosciencies. 4, 116.

Sindelarova, T., Buresova, D., and Chum, J.: 2009, Studia Geophysica et Geodaetica. 53, 403.

Sonwalkar, V.S., Inan, U.S., Bell, T.F., Helliwell, R.A., Chmyrev, V.M., Sobolev, Ya.P., Ovcharenko, O.Ya. and Selegej, V.V.: 1994, J. Geophys. Res.: Space Physics. 99, 17511.

Troitskaya, Yu. I., and Rybushkina, G.V.: 2008, Izvestiya Atmospheric and Oceanic Physics. 44, 621.

Yaroshevich, M.I., and Ingel', L.Kh.: 2006, Izvestiya Atmospheric and Oceanic Physics. 42, 704. 